\title{
EB9, a new antibody for the detection of trophozoites of Pneumocystis carinii in bronchoalveolar lavage specimens in AIDS
}

\author{
J F Wazir, I Brown, E Martin-Bates, D V Coleman
}

\begin{abstract}
Aim-To prepare a monoclonal antibody (EB9) against the trophozoite form of Pneumocystis carinii and to test its efficacy for detecting infection with this organism.

Method-The sensitivity and specificity of the EB9 antibody were assessed by comparing it with other conventional stains (Papanicolaou, Giemsa and Grocott) and 3F6 antibody in 33 bronchoalveolar lavage specimens from HIV positive patients suspected of having $P$ carinii pneumonia.

Results-P carinii infection was detected in 15 of 33 patients. In 14 cases the organism was detected by two or more of the staining methods used; however, EB9 failed to detect infection in two cases which were positive by other staining techniques. In one case $P$ carinii infection was detected by EB9 only.

Conclusion-The results of this study suggest that $\boldsymbol{P}$ carinii infection in the lung may occur in two forms: the cyst form and the trophozoite form, which may explain the observed variation in response to treatment.
\end{abstract}

(F Clin Pathol 1994;47:1108-1111)

In a recent study a group of patients who were negative when tested for Pneumocystis carinii infection on routine cytological staining of bronchoalveolar lavage (BAL) specimens with Papanicolaou, Giemsa, Grocott, and 3F6 monoclonal antibody nevertheless showed a clinical response to treatment for this infection. ${ }^{1}$ This may have been because the staining methods used to detect the cysts were not sensitive enough. An alternative explanation is that these cases may represent infection with the trophozoite form of $P$ carinii, which cannot be detected by the above staining methods. $^{2}$ To prove the latter hypothesis, trophozoites must be detected in BAL specimens. Therefore, to test this hypothesis, a monoclonal antibody (EB9) was raised against $P$ carinii trophozoites and its sensitivity and specificity assessed by comparing it with the conventional stains mentioned earlier.

\section{Methods}

Patients included in this study were attending the AIDS clinic at St Mary's Hospital, London. They presented with an episode of infection characterised by cough, shortness of breath, fever or night sweats, interstitial shadowing on chest radiography, hypoxia, and a low or deteriorating transfer factor on lung function testing.

For each patient, a provisional clinical diagnosis was recorded. One BAL specimen was obtained from each patient.

The monoclonal antibody (EB9) was prepared as follows: BAL specimens from patients with $P$ carinii pneumonia were concentrated by centrifugation. $P$ carinii organisms, including cysts and trophozoites, were then separated from host cells using a Percoll gradient method. An isotonic Percoll solution $(90 \%)$ was prepared by mixing nine volumes of Percoll with one volume of $10 \times$ concentrated phosphate buffered saline (PBS). Four Percoll solutions of different concentrations were prepared by diluting eight, seven, six, and five volumes of $90 \%$ isotonic Percoll solution in two, three, four, and five volumes of PBS (pH 7.4), respectively, giving 80, 70, 60, and $50 \%$ solutions. Percoll solutions were layered in a $15 \mathrm{ml}$ graduated test tube (Falcon), with the heaviest density ( $80 \%)$ solution (4 $\mathrm{ml})$ at the bottom and the lightest $(50 \%)$ solution $(2 \mathrm{ml})$ at the top.

A $1 \mathrm{ml}$ cell suspension from a BAL specimen was placed on the top of gradient and centrifuged at $400 \times g$ for 20 minutes. Following centrifugation, cell fractions at different Percoll layers were collected carefully in $5 \mathrm{ml}$ test tubes and washed three times in PBS $(\mathrm{pH}$ $7 \cdot 4)$ to remove the Percoll. Smears were prepared from the cell pellet from each Percoll layer, and stained using Giemsa to identify the layer containing $P$ carinii cysts and trophozoites. Stained material was mounted in DPX and analysed using light microscopy (Leitz) with $\times 10$ and $\times 40$ objectives.

$P$ carinii organisms were found most frequently in the $50 \%$ Percoll solution layer. Lymphocytes and polymorphs were found in the $70 \%$ Percoll solution layer. Macrophages and red blood cells were observed in the heaviest layer ( $80 \%$ solution). This procedure was repeated using BAL specimens from cases known to be positive for $P$ carinii infection. The organisms were isolated and resuspended in PBS. $P$ carinii trophozoites and cysts were then separated using Dynabeads (electromagnetic beads).

The cell suspension was sonicated and incubated for 45 minutes at room temperature with a 1 in 50 dilution of 3F6 monoclonal antibody. Following incubation, the cell suspension was washed three times in 


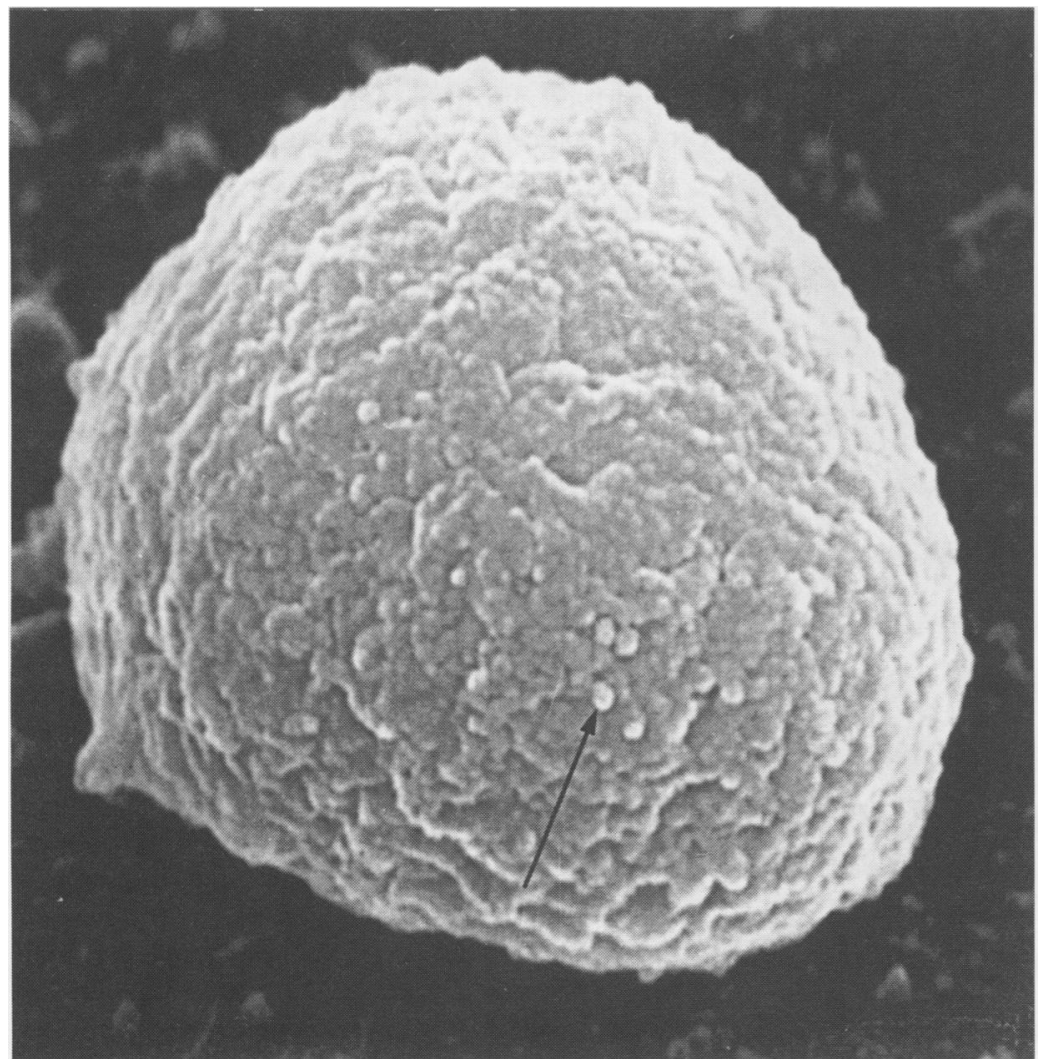

Figure 1 Immunogold labelled (arrow) trophozoite of $P$ carinii using the EB9 monoclonal antibody on scanning electron microscopy (magnification $\times 33500$ ).

PBS and was then incubated with Dynabeads which had been coated with rabbit antimouse antibody for 45 minutes at room temperature. After application of a magnetic Dynabeads applicator, the remaining cell suspension was aspirated with a glass pipette, spread on Thermanox cover slips, and wet fixed in $2 \%$ glutaraldehyde. The trophozoites were visualised using scanning electron microscopy (fig 1).

The EB9 monoclonal antibody was raised against $P$ carinii trophozoites by immunising $\mathrm{Balb} / \mathrm{C}$ female mice three times with trophozoite enriched suspension mixed with Freund's complete adjuvant (Difco Laboratories, UK) in equal volumes. Mouse spleen cells were hybridised with a myeloma cell line in the usual way, ${ }^{3}$ transferred to multiwell plates, and cultured at $37^{\circ} \mathrm{C}$. Once colonies had formed, the supernatant fluid was screened for monoclonal antibody. An enzyme linked immunosorbent assay (ELISA) was performed using a trophozoite enriched suspension. ELISA positive antibodies were then tested on BAL smears known to be positive for $P$ carinii. EB9 antibody which detected trophozoites in nine of the 10 smears was selected for further study. The specificity of the EB9 antibody was further confirmed by scanning electron microscopy using an immunogold technique.

BAL specimens were processed in a high protection cabinet and 10 smears were prepared from each specimen. Eight of the 10 smears were fixed in $95 \%$ ethyl alcohol; the remaining two smears were air dried. Two of the alcohol fixed smears were stained with Papanicolaou and two with Grocott's methenamine silver nitrate stain. The air dried smears were stained with Giemsa. Subsequently, four alcohol fixed smears were stained with the 3F6 (two smears) and EB9 (two smears) monoclonal antibodies using an immunofluorescence method.

Immunocytochemical staining was performed in a moist chamber, as described by Wazir et al. ${ }^{4}$ EB9 and 3F6 were the primary antibodies, while the immunofluorescence labelled rabbit antimouse antibody was the secondary antibody. Smears stained with Papanicolaou, Giemsa, and Grocott were examined using light microscopy (Leitz) with $\times 10$ and $\times 40$ objectives to detect $P$ carinii cysts. EB9 and 3F6 smears were examined using fluorescence microscopy to detect trophozoites.

\section{Results}

Thirty three patients suspected of having $P$ carinii pneumonia were investigated (table). $P$ carinii infection was detected in 15 of the 33 patients on staining with Papanicolaou, Giemsa, Grocott, 3F6, and EB9. These 15 patients also responded well to treatment for $P$ carinii pneumonia. Fourteen of the 15 $P$ carinii positive cases were detected using conventional staining methods (Papanicolaou, Giemsa, and Grocott) and the 3F6 antibody immunofluorescence staining technique. In 12 of the 14 cases $P$ carinii infection was also detected on staining with the EB9

Detection of $P$ carinii in $B A L$ samples from 33 cases using the EB9 antibody

\begin{tabular}{|c|c|c|c|c|c|c|c|c|c|c|c|}
\hline Response to treatment & $\begin{array}{l}\text { Giemsa } \\
\text { Positive }\end{array}$ & Negative & $\begin{array}{l}\text { PAP } \\
\text { Positive }\end{array}$ & Negative & $\begin{array}{l}\text { Grocott } \\
\text { Positive }\end{array}$ & Negative & $\begin{array}{l}3 F 6 \\
\text { Positive }\end{array}$ & Negative & $\begin{array}{l}\text { EB9 } \\
\text { Positive }\end{array}$ & Negative & Total \\
\hline $\begin{array}{l}\text { Positive response } \\
\text { Negative response } \\
\text { Total } \\
\text { Sensitivity (\%) } \\
95 \% \text { CI } \\
\text { Specificity (\%) } \\
95 \% \text { CI } \\
\text { Positive predictive value (\%) } \\
95 \% \text { CI } \\
\text { Negative predictive value (\%) } \\
\text { 95\% CI }\end{array}$ & $\begin{array}{l}14 \\
0 \\
14 \\
93 \cdot 3 \\
68 \cdot 1-9 \\
100 \\
81 \cdot 5-1 \\
100 \\
76 \cdot 84 \\
94 \cdot 7 \\
73 \cdot 9-9\end{array}$ & $\begin{array}{l}1^{\star} \\
18 \\
19\end{array}$ & $\begin{array}{c}14 \\
0 \\
14 \\
93 \cdot 3 \\
\frac{1}{100} \\
\overline{100} \\
\overline{94} \cdot 7\end{array}$ & $\begin{array}{l}1^{\star} \\
18 \\
19\end{array}$ & $\begin{array}{l}14 \\
0 \\
14 \\
93 \cdot 3 \\
\overline{100} \\
\overline{100} \\
\overline{94} \cdot 7 \\
-\end{array}$ & $\begin{array}{l}1^{\star} \\
18 \\
19\end{array}$ & $\begin{array}{c}14 \\
0 \\
14 \\
93 \cdot 3 \\
\overline{100} \\
\overline{100} \\
\overline{94} \cdot 7 \\
\overline{-}\end{array}$ & $\begin{array}{l}1^{\star} \\
18 \\
19\end{array}$ & $\begin{array}{l}13 \\
0 \\
13 \\
86 \cdot 7 \\
59 \cdot 5-9 \\
100 \\
78 \cdot 6-1 \\
100 \\
75 \cdot 3-1 \\
90 \\
68 \cdot 3-9\end{array}$ & $\begin{array}{l}2^{\star \star} \\
18 \\
20\end{array}$ & $\begin{array}{l}15 \\
18 \\
33\end{array}$ \\
\hline
\end{tabular}

PAP = Papanicolaou; $\mathrm{CI}=$ confidence interval.

*One case clinically positive but negative by Giemsa, PAP, Grocott, and 3F6 was detected by EB9.

$\star \star E B 9$ failed to detect two clinically positive cases which were also positive by other stains. 


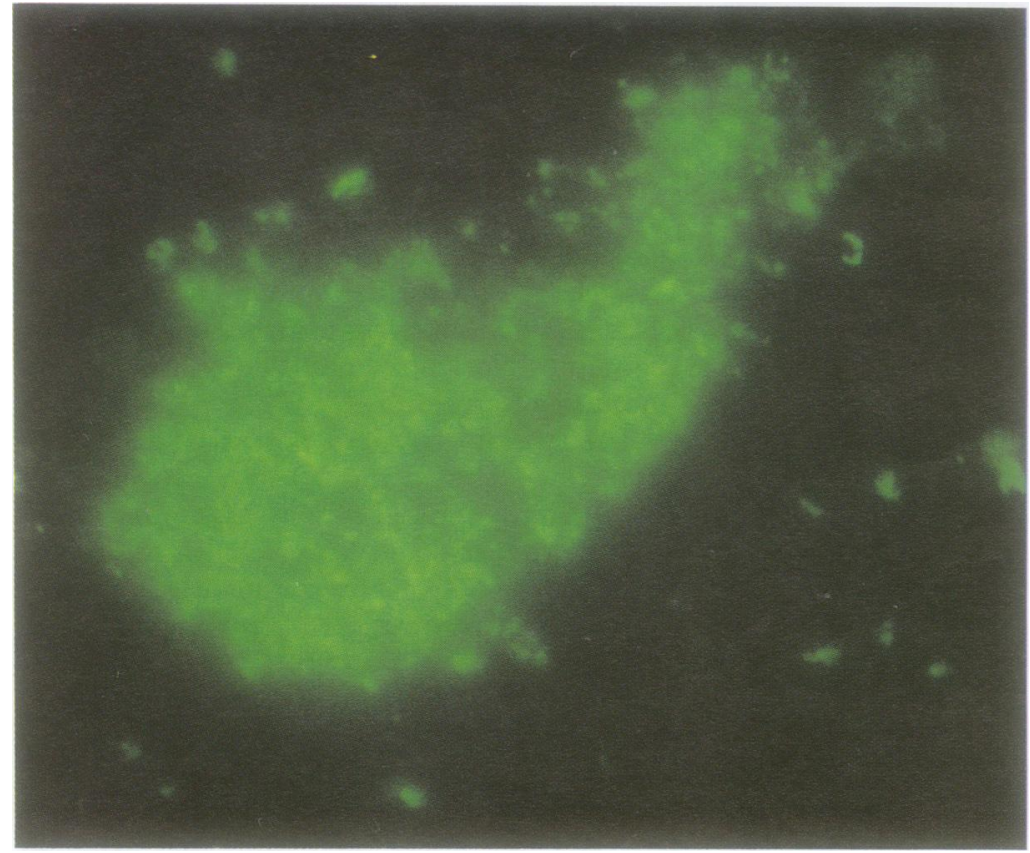

Figure 2 Positive indirect immunofluorescence staining for $P$ carinii trophozoites using the EB9 antibody (magnification $\times 1000$ ).

antibody; in the remaining case infection was detected with the EB9 antibody only.

None of the 18 patients who were negative for $P$ carinii on all staining methods responded to treatment with intravenous co-trimoxazole. Culture was positive for Mycobacterium tuberculosis in three cases, for Haemophilus influenzae in two, for Streptococcus in five, for Staphylococcus in one, and for both Streptococcus and $H$ influenzae in one. Pulmonary Kaposi's sarcoma was detected in one case on histological examination. In six cases culture for $M$ tuberculosis was not performed.

\section{Discussion}

The trophozoites of $P$ carinii are $2-4 \mu \mathrm{m}$ in length, and appear as unicellular structures with a thin wall and numerous surface projections known as membranotubular extensions on electron microscopy. ${ }^{5}$ On Giemsa stained smears, trophozoites may appear as tiny specks with no further characterisation. Immunocytochemical evaluation, therefore, was mandatory. On smears stained with the EB9 monoclonal antibody, trophozoites appear as pleomorphic, small, thin walled structures connected to each other by thin membranes (fig 2).

Isolation and separation of $P$ carinii trophozoites from the cystic form and host cells in BAL specimens is an important prerequisite for the preparation of murine monoclonal antibodies directed specifically against trophozoites. As yet, no technique has been described for complete separation of the trophozoite and cystic forms of $P$ carinii. Many authors, however, have attempted to separate cysts from host cells. In 1986 Kovacs et $a l^{6}$ separated $P$ carinii cysts from lung cells using a Percoll gradient. Taylor and Easmon described another method for the separation of $P$ carinii cysts from rat lung tissue homogenates using a unit gravity sedimentation chamber.

In this study, however, a discontinuous Percoll gradient was used in preference to the unit gravity sedimentation chamber for the initial separation of $P$ carinii from host cells for the following reasons. The initial cost of the unit gravity sedimentation chamber is very high, separation is incomplete, and the method is very time consuming. The problem of purification and identification of the gradient layer containing $P$ carinii was resolved by centrifuging the gradient at various speeds until a high level of purification was achieved.

EB9 was specific for the trophozoite form of $P$ carinii. It also reacted with alveolar macrophages in smears from BAL specimens containing $P$ carinii suggesting that EB9 can detect phagocytosed trophozoites. Evidence for this has been provided by the in vitro studies of Von Behren and Pesanti ${ }^{8}$ who showed that $P$ carinii can be phatocytosed by macrophages. Pfitzer et $a l^{9}$ described inclusions in alveolar macrophages, interpreted as ingested pneumocysts, on fluorescence microscopy of Papanicolaou stained smears from BAL specimens.

The sensitivity of EB9 was determined by comparing the staining pattern with response to treatment and was found to be $86 \cdot 7 \%$. EB9 was $6.6 \%$ less sensitive than $3 \mathrm{~F} 6$ and the other conventional stains.

In routine clinical practice a combination of EB9 and 3F6 or EB9 alone may be more effective for detecting $P$ carinii trophozoites than staining by conventional methods. Based on the results presented here, we suggest that $P$ carinii pneumonia may present as one of two forms: one in which the cysts predominate, while trophozoites predominate in the other. This could explain why some cases suspected of having $P$ carinii pneumonia are negative for the cyst form on conventional staining, but respond to treatment with co-trimoxazole. This is in accordance with the life cycle of $P$ carinii. In the rat cysts predominate under adverse conditions such as those in the immunocompetent host, whereas trophozoites predominate when conditions are more favourable - that is, in the immunodeficient host. ${ }^{5}$ The method described here may also compare favourably with the polymerase chain reaction. ${ }^{10}$

In conclusion, BAL and induced sputum samples from patients with AIDS should be stained initially with Papanicolaou, Giemsa, and Grocott's methenamine silver nitrate. This permits the detection of $P$ carinii and concurrent infections such as Candida or Aspergillus. Immunocytochemical staining with EB9 should be reserved for cases negative for $P$ carinii infection on cytochemical stains but who are thought to have $P$ carini induced pneumonia. The EB9 monoclonal antibody may be of value for detecting these cases. 
1 Wazir JF, Macrorie SG, Coleman DV. Evaluation of the sensitivity, specificity, and predictive value of mono-
clonal antibody $3 \mathrm{~F} 6$ for the detection of Pneumocystis clonal antibody $3 \mathrm{~F} 6$ for the detection of Pneumocystis carinii pneumonia in bronchoalveolar lavage specim

2 Linder E, Lundin L, Vorma H. Detection of Pneumocysti carinii in lung-derived samples using monoclonal antibodies to an $82 \mathrm{KDa}$ parasite component. 7 Immunol Methods 1987;98:57-62.

3 Engvall E, Perlmann P. Enzyme linked immunosorben assay, ELISA. III. Quantitation of specific antibodies by enzyme-labelled anti-immunoglobulin in antigen-coated tubes. F Immunol 1972;109:129-35.

4 Wazir JF, Martin-Bates E, Woodward G, Coleman DV. Evaluation of immunocytochemical staining as a method of improving diagnostic accuracy in a routin cytopathology laboratory. Cytopathology 1991;2:75-82.

5 Matsumoto $\mathrm{Y}$, Yoshida $\mathrm{Y}$. Advances in pneumocystis biology. Parasitol Today 1986;2:137-42.
6 Kovacs JA, Gill V, Swan JC, Ognibene F, Shelhamer J, Parrillo JE, et al. Prospective evaluation of a monoclonal antibody in the diagnosis of Pneumocystis carinii pneumonia. Lancet 1986;ii:1-3.

7 Taylor MB, Easmon CSF. Separation of Pneumocystis carinii from the lung of the steroid-suppressed rat. FEMS 1990;70:49-54.

8 Von Behren LA, Pesanti B. Uptake and degradation of Pneumocystis carinii by macrophages in vitro. $\mathrm{Am} \mathrm{Rev}$ Respir Dis 1978;118:1051-9.

9 Pfitzer P, Wehle K, Blanke M, Burrig KF. Fluorescence microscopy of Papanicolaou-stained bronchoalveolar lavage specimens in the diagnosis of Pneumocystis carinii [letter]. Acta Cytologica 1989;33:557-9.

10 Lipschik GY, Gill VJ, Lundgren JD, Andrawis VA, Nelson NA, Nielsen JO, et al. Improved diagnosis of Pneumocystis carinii infection by polymerase chain reaction on induced sputum and blood. Lancet 1992;340:203-6. 